\title{
Genetic Effects on Mating Success and Partner Choice in a Social Mammal
}

\author{
Jenny Tung, ${ }^{1, \varkappa}, \dagger$ Marie J. E. Charpentier, ${ }^{2, \dagger}$ Sayan Mukherjee, ${ }^{3}$ Jeanne Altmann, ${ }^{4,5}$ and \\ Susan C. Alberts ${ }^{5,6}$
}

1. Department of Human Genetics, University of Chicago, Chicago, Illinois 60637; Department of Evolutionary Anthropology, Duke University, Durham, North Carolina 27708; and Duke Population Research Institute, Duke University, Durham, North Carolina 27708; 2. Centre d'Ecologie Fonctionnelle et Evolutive-CNRS, UMR 5175, 1919 Route de Mende, 34293 Montpellier Cedex 5, France; 3. Department of Statistical Science, Duke University, Durham, North Carolina 27708; Department of Computer Science, Duke University, Durham, North Carolina 27708; and Department of Mathematics, Duke University, Durham, North Carolina 27708; 4. Department of Ecology and Evolutionary Biology, Princeton University, Princeton, New Jersey 08540; 5. Institute of Primate Research, National Museums of Kenya, Nairobi, Kenya; 6. Department of Biology, Duke University, Durham, North Carolina 27708

Submitted October 16, 2011; Accepted February 24, 2012; Electronically published May 17, 2012

Online enhancement: appendix. Dryad data: http://dx.doi.org/10.5061/dryad.4r9h61v8.

ABSTRACT: Mating behavior has profound consequences for two phenomena-individual reproductive success and the maintenance of species boundaries - that contribute to evolutionary processes. Studies of mating behavior in relation to individual reproductive success are common in many species, but studies of mating behavior in relation to genetic variation and species boundaries are less commonly conducted in socially complex species. Here we leveraged extensive observations of a wild yellow baboon (Papio cynocephalus) population that has experienced recent gene flow from a close sister taxon, the anubis baboon (Papio anubis), to examine how admixturerelated genetic background affects mating behavior. We identified novel effects of genetic background on mating patterns, including an advantage accruing to anubis-like males and assortative mating among both yellow-like and anubis-like pairs. These genetic effects acted alongside social dominance rank, inbreeding avoidance, and age to produce highly nonrandom mating patterns. Our results suggest that this population may be undergoing admixture-related evolutionary change, driven in part by nonrandom mating. However, the strength of the genetic effect is mediated by behavioral plasticity and social interactions, emphasizing the strong influence of social context on mating behavior in socially complex species.

Keywords: hybridization, assortative mating, consortship, baboons, dominance rank.

\section{Introduction}

Mating behavior plays a key role in determining individual reproductive success, shaping population genetic structure, and maintaining species boundaries. With the exception

* Corresponding author; e-mail: jt5@duke.edu.

$\dagger$ These authors contributed equally to this work.

Am. Nat. 2012. Vol. 180, pp. 113-129. (C) 2012 by The University of Chicago. 0003-0147/2012/18001-53397\$15.00. All rights reserved.

DOI: $10.1086 / 665993$ of studies that have focused on a variety of general "good genes" or compatibility effects (reviewed in Jennions and Petrie 2000; Tregenza and Wedell 2000; Neff and Pitcher 2005; Kempenaers 2007; Hettyey et al. 2010), most detailed studies of genetic effects on mating behavior in natural populations have focused on socially monogamous, solitary, or semisolitary species in which mating behavior involves comparatively stereotyped behavior patterns that occur during short, well-defined time windows (Veen et al. 2001; Haesler and Seehausen 2005; Mávarez et al. 2006; Pfennig 2007). These studies indicate that a strong genetic effect on one or a few traits involved in mate choice can be a powerful general predictor of mating outcomes. For instance, genetic variation has a strong influence on wing coloration in the Heliconius butterfly complex, and wing patterning appears to be the central factor guiding assortative mating preferences within this group (Kronforst et al. 2006; Mávarez et al. 2006).

In highly social species, however, mating behavior occurs in the context of complex social interactions, and any genetic effects on mating behavior will operate within this background. For instance, in many group-living primates, individuals reside in social units that include multiple individuals of both sexes (Smuts et al. 1987). Mating behavior takes place in the context of long-term, individually differentiated social relationships between individuals. Both males and females may express mating preferences, and aspects of social group structure, such as the strength of social dominance hierarchies, may impose further constraints on these preferences (Bercovitch 1995; Smuts 1985; Cowlishaw and Dunbar 1991; Altmann and Alberts 2003b; Gesquiere et al. 2007). The penetrance of genetic effects on mating outcomes in species for which individual dom- 
inance rank, social integration, and social relationships are known to have a strong impact on mating, remains an outstanding question.

To evaluate the impact of genetic effects on mating events in highly social species will require models that consider genetic effects alongside the behavioral and demographic effects that are already known to be in play for such species, such as male social status (e.g., dominance rank; Cowlishaw and Dunbar 1991; Ellis 1995), age (Muller et al. 2006), condition-dependent traits and ornaments (Petrie et al. 1991; Kempenaers 2007), density dependence (e.g., Clutton-Brock et al. 1997; Coltman et al. 1999; Alberts et al. 2003), and sex-specific interests (reviewed in Halliday 1988; Gavrilets et al. 2001; Chapman et al. 2003). Hence, an analysis of potential genetic effects on mating behavior in such species requires a data set that encompasses variance not only in genetic traits but also in a range of other traits and environmental conditions that may affect mating behavior. This in turn requires a large amount of direct observational data on multiple mating events involving a large number of individuals across multiple demographic conditions.

These criteria are met by long-term observations of mating behavior in the yellow baboons (Papio cynocephalus) of the Amboseli basin. These baboons have been the subjects of continuous behavioral, demographic, and ecological monitoring since 1971 (Altmann 1980; Alberts and Altmann 2003; Alberts et al. 2003; Altmann et al. 2010). A number of social and demographic predictors of mating behavior have already been identified in this population. Social dominance rank has a strong effect on male mating success and reproductive success, and male density modifies the relationship between rank and mating success such that high-ranking males have less of an advantage in larger groups (Alberts et al. 2003, 2006). For females, dominance rank has a significant effect on lifetime reproductive success (Altmann et al. 1988; Altmann and Alberts 2003a), but it is not known to affect female mating success in this species. Female fertility changes with age (Beehner et al. 2006b) and female parity is a predictor of infant survival and growth (Altmann et al. 1988; Altmann and Alberts 2005), suggesting a basis for male mate choice that is supported by empirical evidence (Gesquiere et al. 2007). In addition, Amboseli baboons exhibit strong inbreeding avoidance (Alberts and Altmann 1995; Alberts 1999).

Recent observations of hybridization in this population have introduced the possibility of detecting measurable genetic effects on mating behavior alongside the above known predictors. The occasional immigration of anubis baboons (Papio anubis) into the Amboseli basin has resulted in a population that is now primarily composed of yellow baboons (P. cynocephalus) but that also includes a substantial and increasing fraction of hybrid animals, in- cluding a few individuals that are more anubis-like than yellow-like (Alberts and Altmann 2001; Tung et al. 2008). Papio cynocephalus and P. anubis are morphologically distinct sister taxa (anubis baboons have darker pelage and a more robust build relative to the more gracile yellow baboons; see articles by Alberts and Altmann [2001] and Jolly [1993] for detailed discussions of these and other phenotypic differences) that inhabit geographically distinct ranges and co-occur only within relatively narrow hybrid zones between those ranges (Jolly 1993; Alberts and Altmann 2001; Newman et al. 2004; Zinner et al. 2009; Charpentier et al. 2012). Anubis baboons and yellow baboons are similar enough that they are sometimes considered subspecies rather than distinct species (e.g., Jolly 1993). They produce viable and fertile offspring and show little evidence of hybrid dysgenesis (Ackermann et al. 2006; Tung et al. 2008). Additionally, they are relatively recently diverged: analyses of mitochondrial DNA place anubisyellow divergence at 150,000-172,000 years ago (Newman et al. 2004), and genetic evidence for historic introgression in East Africa indicates that anubis and yellow baboons in Kenya may be even more closely related (Charpentier et al. 2012). At the same time, the possibility of different ecological specializations in these two taxa is suggested by genetic data, which clearly differentiate anubis and yellow populations (Tung et al. 2008; Charpentier et al. 2012). Further, the genetic structure of baboon populations in southern Kenya exhibits a sharp transition between the two taxa at the hybrid zone where their respective ranges meet (Charpentier et al. 2012).

Our previous work on hybrid baboons in Amboseli has identified a strong effect of genetic background on lifehistory traits (Charpentier et al. 2008). Males and females with a higher proportion of anubis admixture (defined here as the "hybrid score"; see "Material and Methods") reached physical maturity earlier than animals with a yellow baboon genetic background, likely reflecting a pattern of hybrid intermediacy (e.g., Ackermann et al. 2006). The effect was particularly pronounced in males (Charpentier et al. 2008). The strength of these effects, combined with the genetic diversity introduced by hybridization in Amboseli, led us to hypothesize that genetic background might have other effects on behavior or life history, including assortative mating by genetic background, that may help to maintain the narrowness of the hybrid zone. Such assortative mating has been observed in a number of invertebrate and vertebrate species (Boughman 2001; Seehausen and Schluter 2004; Mávarez et al. 2006; reviewed in Tregenza and Wedell 2000) but has rarely been documented among social large mammals.

Here we evaluate the impact of genetic traits on mating behavior-specifically, individual hybrid score and assortative mating by hybrid genetic background, but also in- 
dividual genetic diversity and genetic distance between mating pairs-in the context of known behavioral and demographic sources of variance in mating patterns. To do this, we synthesized 78 group-years of data, where a group-year represents 1 year for one social group. Our analyses combined mating behavior, group demography, and social dominance data with genotype data on 236 wild reproductive baboons living in eight different social groups. We also took advantage of the fact that social groups differed in their demographic makeup, in order to assess how mating behavior varied across different demographic contexts. To our knowledge, this kind of assessment is rare, but it is essential for understanding how the intensity of selection on traits related to these predictor variables fluctuates over time and space. We focused specifically on the occurrence of sexual consortships, which represent sustained mate-guarding episodes involving an adult male and a sexually active (i.e., estrous) female (Gesquiere et al. 2007). Gaining and maintaining sexual consortships imposes costs on males because it requires nearconstant vigilance to maintain close proximity to estrous females and guard against incursion by other males (Alberts et al. 1996). The reward for this effort can be significant: the proportion of available consortship time that a male obtains is highly predictive of paternity success in this population (Alberts et al. 2006). Thus, sexual consortships represent readily observable investments in reproduction that also incur discernible costs.

\section{Material and Methods}

\section{Study Subjects}

The Amboseli basin is a semiarid short-grass savanna in southern Kenya that is inhabited by a natural population of primarily yellow baboons (Papio cynocephalus) that experiences some admixture with anubis baboons (Papio anubis) that immigrate from outside the basin (Samuels and Altmann 1986; Alberts and Altmann 2001; Tung et al. 2008). Individuals included in this study were members of eight intensively studied social groups that were followed between January 1980 and December 2007 (table $\mathrm{A} 1$, available online). All individuals were members of one of two original study groups monitored in the early 1980 s or were members of groups that resulted from permanent fissions of these original groups (Alberts et al. 2003; Altmann and Alberts 2003a).

All individuals in the study population were recognized on sight by observers, on the basis of unique physical characteristics. Females in this species are philopatric, while males disperse from their natal group at a median of 8.5 years of age (young adulthood) and may undergo subsequent secondary dispersal as adults (Alberts and Alt- mann 1995). All individuals born in the study population-all females, and males that remain within the study population even after dispersal from their natal groupwere identified at birth and followed throughout their lives or until they emigrated from the study population. Consequently, ages for all female subjects of this study were known to within a few days (we did not include male age as a predictor of consortship behavior because of the close link between male age and male dominance rank).

\section{Mating Behavior}

In both yellow baboons and anubis baboons, cycling females (those that are experiencing regular sexual cycles and are therefore reproductively available) exhibit highly visible sexual skin swellings that indicate ovarian cycle phase. Conception is most likely to occur when these swellings reach maximum size (Wildt et al. 1977), which typically occurs during the 5-day window preceding the onset of deturgescence (Wildt et al. 1977; Gesquiere et al. 2007). Mating behavior occurs most frequently in this 5-day window (Gesquiere et al. 2007). For the purposes of this study, we therefore considered the mating behavior that occurred within this window of time.

Males of many animal species, including baboons and a number of other primates, engage in mate guarding, a taxonomically widespread mating tactic that involves maintaining close proximity to and preventing competitors from gaining access to a potential mate (CluttonBrock 1989; Andersson 1994). In primates, mate-guarding episodes are usually referred to as "sexual consortships." These episodes are identifiable as periods of close and persistent following of an estrous female by an adult male that may last from several hours to several days and that involve affiliative and sexual behaviors between the consort partners (Seyfarth 1978). Participation in consortships is a major means of achieving mating success for male baboons (Bercovitch 1995; Altmann et al. 1996; Alberts et al. 2003) and other primates (Melnick and Pearl 1987; Smuts 1987). The incidence of consortships and the identity of the participants was recorded throughout the study period, using all-occurrences sampling conducted by trained field observers, as described by Altmann (1974; see also the Amboseli Baboon Research Project Monitoring Guide at http://www.princeton.edu/ baboon). Consortship and other demographic and behavioral data were extracted from our long-term relational database, Babase (Pinc et al. 2009).

The data set for mating behavior covered all group-year combinations that occurred from January 1980 to December 2007 (table A1), with the following exceptions. First, we excluded data from social group-year combinations that fell during fission processes, because of the difficulty 
of unambiguously assigning individuals to particular groups during these processes. Second, we excluded data from years in which data collection on mating behavior was discontinuous. After excluding these cases, the resulting data set covered 78 total group-years of monitoring data over a period of 28 years (table A1).

\section{Statistical Analyses}

For each group-year of monitoring data, we collated data on mating behavior for all adult females that had previously conceived and all adult males (a male was defined as an adult when he had permanently attained social dominance rank over at least one other adult male). After applying several filters to these data (appendix), the resulting data set consisted of 12,141 possible consortship pairings. These pairings included 121 unique males and 115 unique females observed over the course of 1,601 unique female estrous cycles.

We modeled the consortship data as a set of binary events, where each line of data corresponded to an adult female-adult male pair for which a consortship was possible (i.e., a pair composed of members of the same social group during at least 1 day of the 5-day ovulatory window of one of the female's estrous cycles). We assigned a value of 1 to the pair if they were observed to consort at least once during the estrous cycle and a value of 0 if the pair was never observed to consort during the estrous cycle. Female-male dyads could therefore be represented multiple times in the overall data set but only once per unique estrous cycle.

In order to explain variation in the probability of a consortship occurring, we modeled the $0 / 1$ response variable using multivariate logistic regression. Because individuals were unequally represented in the data set and because most of the explanatory variables did not follow standard parametric distributions (figs. A1-A6, available online), we assigned a $P$ value for each explanatory variable via permutation tests. This approach allowed us to compare the actual pattern of mating events to a set of permuted data sets in which consortships occurred at random but where (1) unequal representation of individuals was held constant and (2) the number of total consortships was approximately equal to the number of total consortships in the true data set.

To produce each permuted data set, we first calculated the proportion of dyads within each unique estrous cycle for which a consortship occurred (i.e., where a malefemale dyad was assigned a value of 1). That is, if there were five potential sets of consorting pairs during a given estrous cycle but only one of those five pairs actually consorted, the proportion of dyads for which a consortship occurred was 0.20 . We termed this value the "consortship probability" for that estrous cycle. Second, we permuted the set of consortship probabilities across estrous cycles. Finally, for each estrous cycle, we assigned each line of data a value of 1 (corresponding to occurrence of a consortship), with probability equal to the newly assigned consortship probability. This procedure maintained the structure of the explanatory variables in the data, the representation of each individual in the data set, and the distribution of consortships per estrous cycle, while scrambling the cases of successful consortships across the data set. We then fitted the model to the permuted data set in the same manner as the original data set and generated parameter estimates for each model effect. The $P$ value for each model effect corresponds to the proportion of instances in which the estimated effect size from a permuted data set exceeded the estimated effect size for the true data set, out of 1,000 permutations.

\section{Explanatory Variables}

Distributions and summary statistics for the explanatory variables in the data set are provided in the appendix (table A2, available online; figs. A1-A6).

Individual Identity. In order to deal with interindividual differences that are not explicitly taken into account by our explanatory variables, we included the identity of each male and the identity of each female as random effects in the model (individuals must have had at least 10 consortship opportunities, and thus must have been present for at least 10 estrous cycles, in order to be included in the data set).

Conceptive versus Nonconceptive Cycles. For each estrous cycle, retrospective analyses performed after the cycle had ended enabled us to identify it as a conceptive cycle (i.e., one that resulted in the conception of an offspring) or a nonconceptive cycle (Beehner et al. 2006a; Gesquiere et al. 2007). Alpha-male baboons target conceptive (as opposed to nonconceptive) cycles for intense investment in mate guarding, with the consequence that alpha males father more offspring than expected from a simple rankbased model of mating access (Bulger 1993; Weingrill et al. 2000; Alberts et al. 2006; Gesquiere et al. 2007). In addition, female baboons in Amboseli exhibit larger sex skin swellings during conceptive cycles than nonconceptive cycles, and they also tend to have higher levels of fecal estrogens (Gesquiere et al. 2007). Hence, the probability of a consortship occurring between a male-female pair during a conceptive cycle may differ from the probability of a consortship occurring during a nonconceptive cycle, and we therefore included the outcome of an estrous cycle 
(conceptive/nonconceptive) as an explanatory variable in the overall model.

Dominance Rank. Dominance rank confers priority of access to important resources in baboons (Barton 1993; Barton and Whiten 1993), including, for males but not females, access to mates (Hausfater 1975; Alberts et al. 2003, 2006; Weingrill et al. 2003). The dominance ranks of the individuals involved in a potentially consorting pair may thus have an important influence on whether a consortship actually occurs. Consequently, we considered male dominance rank, female dominance rank, and the interaction between the two as potential explanatory variables in the model. Below we describe the manner in which we consider each of these possible effects.

In baboons, dominance rank is linear within sexes and measured by the ability of dominant individuals to consistently win agonistic encounters with subordinates. Male dominance ranks and female dominance ranks were assigned for each month on the basis of the outcomes of these encounters during that month (Hausfater 1975; Alberts et al. 2003). For females, we had no a priori expectation that rank would exhibit a particular functional relationship with mating behavior. Therefore, we modeled female rank as an untransformed variable corresponding to the ordinal rank of each individual (higher ranks have lower numbers). For males, previous work in this population indicated that the relationship between male rank and mating success depends in part on the number of adult males present in the social group (Alberts et al. 2003; see Alberts et al. 2006 for similar results on paternity success). High rank confers the most benefits in groups with few males and progressively fewer benefits as the number of males in the group increases. In other words, the fit of a dominance rank-based priority-of-access model worsens as the number of adult males in a group increases (Alberts et al. 2003). In order to take this dependency into account, we modeled male dominance rank, using a transformed male rank variable, $\rho^{\prime}$, based on the exponential distribution. Specifically, we defined $\rho^{\prime}=\lambda_{\mathrm{m}} e^{-\lambda_{\mathrm{m}} \rho}$, where $\rho$ corresponds to the untransformed rank for a given male, $\lambda_{\mathrm{m}}$ describes the rate at which $\rho^{\prime}$ exponentially decreases with lower untransformed rank, and $\lambda_{\mathrm{m}}$ is dependent on the number of males $m$ in the group in the manner described by earlier results for this population (Alberts et al. 2003, 2006; appendix; fig. A7, available online). High values of $\rho^{\prime}$ therefore correspond to higher-ranking individuals in groups with fewer adult males.

Age. Because fertility declines in old age in females (Beehner et al. 2006b; Altmann et al. 2010), we considered the age of the female in a potentially consorting pair as a possible predictor of consortship events. In addition to a linear effect of female age, we also considered the possibility that the probability of consortship follows the same relationship with female age as the probability of conception: females are most likely to conceive around age 14 years, and the probability of conception falls off at younger and older ages (Beehner et al. 2006b). Therefore, we also included a parameter in the model that would capture a similar effect for consortships, for which the maximum probability of consortship with respect to female age occurred at age 14 years and consortship probabilities decreased for older and younger females, with the greatest difference observed for the youngest and oldest females in the data set (appendix). Birth dates were known for all females in the study, within a margin of error of a few days.

In male baboons, age strongly predicts dominance rank such that individuals generally attain high rank when they are relatively young and in their prime and then fall in rank throughout their lives (Alberts et al. 2003). Because we could not disentangle the effects of age and rank and because male rank is likely to have a more direct effect on mating behavior than male age, we did not include male age in our model.

Group Composition. The number of individuals within a group influences competition for resources and the availability of mates. We therefore incorporated two grouplevel demographic effects in the consortship model: the number of adult males (which indexes the degree of malemale competition) and the number of adult females (which indexes the likelihood that multiple females will be reproductively available at the same time and also captures density-dependent effects on female reproduction in the social group in which the focal dyad resided; see Bulger and Hamilton 1987; Altmann and Alberts 2003a; Beehner et al. 2006b).

Pairwise Genetic Distance. Genetic distance between a potentially consorting pair may influence the probability that they actually consort. We included the Queller-Goodnight (QG) estimate of relatedness (Queller and Goodnight 1989) between the male and the female in each malefemale pair as an explanatory variable in the consortship model (previously calculated from 14 highly polymorphic microsatellite loci; for more details, see Buchan et al. 2003; Alberts et al. 2006; Van Horn et al. 2007). We tested the following two hypotheses: (1) pairs were less likely to mate with decreasing genetic distance, using the raw QG relatedness estimate, and (2) pairs were more likely to mate if they were neither genetically close (i.e., related) nor genetically distant (using marker-based estimates instead of pedigree estimates allowed us to assess genetic distance among nonkin as well). To test the latter hypothesis, we 
fitted a quadratic term for genetic distance centered on 0 . We note that, because of the relatively small number of loci in our data set, the genetic distance estimates are likely to be noisy relative to pedigree-based measures. Such noise is unlikely to produce a false-positive result in the specific analysis we pursued here (the genetic distance effect is more likely to be slightly underestimated) because all dyads, and not just those with a biased probability of consorting, are subject to the same statistical noise. However, we caution against interpreting our results in the framework of discrete kinship categories (see Van Horn et al. 2007).

Individual Genetic Diversity. Genetic diversity within the genome of an individual has been suggested to confer mating behavior-related benefits (Partridge 1983; Kempenaers 2007; Neff and Pitcher 2008). We therefore estimated the proportion of loci that were heterozygous for a given individual among the overall set of genotyped markers for that individual (on the basis of 14 highly polymorphic microsatellite loci; see Charpentier et al. 2008) as our index of genetic diversity. We included male genetic diversity and female genetic diversity as explanatory variables in the model. Although these markers were initially developed for work in yellow baboons, in earlier work we tested for differences between genetic diversity levels at these loci in unadmixed yellow baboons and unadmixed anubis baboons and found no significant effect of species membership (Charpentier et al. 2012).

Hybrid Background and Assortative Mating with Respect to Genetic Background. To test the possibility that mating behavior-particularly, assortative mating-plays a role in the dynamics of this hybrid zone, we included genetic estimates of anubis admixture (assigned in Tung et al. 2008) for both the male and female in each pair in our mating models. We also tested the hypothesis of assortative mating with respect to genetic hybridity, using the following pairwise assortative mating index, $a$ :

$$
a=\max \left(h_{\mathrm{m}} \times h_{\mathrm{f}},\left(1-h_{\mathrm{m}}\right) \times\left(1-h_{\mathrm{f}}\right)\right),
$$

where $h_{\mathrm{m}}$ is the hybrid score of the male and $h_{\mathrm{f}}$ is the hybrid score of the female, and both $h_{\mathrm{m}}$ and $h_{\mathrm{f}}$ fall in the interval $[0,1]$ (where 0 equates to a full yellow baboon and 1 equates to a full anubis baboon). This index also ranges from 0 to 1 , and it assigns the highest possible value to assortatively mating pairs for which both individuals have very low hybrid scores (both are yellow baboons) or both individuals have very high hybrid scores (both are anubis baboons). The index produces the lowest possible values to disassortatively mating pairs in which individuals have very dissimilar hybrid scores (i.e., one is a yellow baboon and one is an anubis baboon). Pairs of individuals that have similar scores but are themselves hybrids are assigned intermediate values; even though these individuals are mating with individuals with similar hybrid scores as their own, these pairs do not strongly reflect preferential mating that would reinforce species boundaries.

\section{Variance in Effect Size across Social Groups}

The final data set incorporated data from eight different social groups that were observed during different periods of time from 1980 to 2007. In order to assess the stability of the significant effects we observed in the full data set over time and across social groups, we repeated our analysis on individual social groups alone, for the six groups for which we had the most data. Because of the smaller data sets available for each social group and the smaller number of individual random effects we needed to fit, we included data from any individual that had at least five opportunities to participate in a consortship pairing (as opposed to 10 opportunities in the larger analysis).

\section{Predicting Mating Behavior: Rank Effects and Genetic Effects}

The results of the overall consortship model demonstrated that two major groups of explanatory variables consistently influenced the probability that a consortship would occur: genetic effects (mediated by male hybrid score, male genetic diversity, assortative mating by genetic background, and pairwise genetic distance) and rank effects (mediated by male rank and an interaction between male rank and female rank). In order to assess the relative importance of genetic effects and rank effects, we investigated which set of effects better predicted whether pairs of individuals that were not used to fit a consortship model actually consorted.

Specifically, we used a leave- $k$-out procedure in which we randomly removed $k=500$ possible consortship pairings from the full data set and then refit a consortship model on the remaining $n-k$ lines of data. In one case, we used only the four genetic variables that were significant in the complete model to fit the reduced data set. In the alternative case, we used only the two rank-related variables that were significant in the complete model to fit the reduced data set. In both cases we used these reduced models, in combination with the values for the explanatory variables in the 500 missing lines, to calculate the probability of consortship for each line of data in $k$.

We then compared these probabilities to the actual known outcomes for the 500 pairs of individuals that were not used to fit the reduced models. We repeated this procedure 100 times for each case (genetic-effects only and rank-effects only) and calculated the area under the curve 
(AUC) for each iteration. The AUC ranges from 0 to 1 and provides a measure of the trade-off between increasing the number of true positives and minimizing the number of false positives when predicting the value of a binary variable, over all possible thresholds. An AUC of 0.5 is equivalent to random prediction; an AUC greater than 0.5 corresponds to better-than-random prediction, where an AUC of 1.0 is equivalent to perfect prediction (no tradeoff between calling true positives and accumulating false positives); and an AUC of less than 0.5 corresponds to worse-than-random prediction. We also performed the same calculations on a permuted data set (i.e., where consortships were permuted randomly with respect to the explanatory variables) to establish a null distribution for the predictive ability of the data (expected to have a mean AUC of 0.5, equivalent to random prediction). Finally, we assessed differences in the predictive power of a rank-based model and a genetic effects-based model, as well as differences between each of these models and a null model based on permuted data, using $t$ tests.

\section{Dissection of the Assortative Mating Effect}

The results of the full consortship model also indicated that assortative mating by genetic background played a role in influencing consortship behavior in Amboseli. In other words, consortships were significantly more likely to occur between individuals that were both yellow baboonlike or both anubis baboon-like than between pairs that were dissimilar in this respect.

In order to better understand the factors driving this assortative mating pattern, we calculated an estimate of each individual's tendency to mate assortatively (as opposed to evaluating the population mean effect). First we calculated the mean assortative index (MAI) for an individual as the mean value of $a$ (the pairwise assortative mating index described above) in all consortships involving a given individual; we limited this analysis to individuals that consorted at least five times in the overall data set. Then we compared the value of this MAI with the distribution of an equivalent value from permuted data. A higher MAI value for a given baboon in the true data set than in most or all of the permuted data sets indicated that the consortships in which that individual engaged were unusually assortative given that individual's potential partners; conversely, a low MAI suggests that the individual was consorting disassortatively relative to his or her possible mating partners. To estimate the strength of assortative mating for an individual, we calculated the proportion of permuted data sets in which the MAI was higher than the true MAI for the same individual. We then used these values to assess whether the population-level assortative mating effect stemmed from the behavior of males, females, or both sexes and whether the tendency toward assortative mating is itself dependent on an individual's genetic background as captured by his or her hybrid score. We compared the distribution of evidence for strength of assortative mating preferences between males and females, using a two-tailed Wilcoxon summed ranks test.

\section{Results \\ Results of the Full Consortship Model}

The results of our overall model for sexual consortship occurrence (table 1) indicate that male genetic background and genetic diversity had strong and significant influences on consortship probabilities in the Amboseli population. Specifically, the probability of a consortship increased with higher male hybrid score $(P<.001)$ and higher male genetic diversity $(P<.009)$. As expected, male social characteristics-in particular, social dominance rank-also had a significant effect, such that higher male dominance rank increased the probability of a consortship $(P<.001)$. In other words, a sexual consortship was more likely to occur when the male in a potential pair was more anubislike, more genetically diverse, and higher in the male dominance hierarchy (fig. 1).

The effects of female characteristics on consortship occurrence were less marked. We found no significant effect of female hybrid score, female genetic diversity, or female dominance rank on the probability of consortship between a given pair, indicating that the impact of these effects is sex-biased toward males. However, our data did suggest a possible weak effect of female age on consortship occurrence. Pairs in which the female was older tended to be less likely to engage in a consortship $(P=.025)$, and females that were middle-aged tended to be the most likely to participate in consortships $(P=.065)$. This age-based trajectory thus loosely mirrors the relationship between age and fertility for female baboons in Amboseli, which is lowest in very late adulthood (as well as in adolescence, which we did not consider in this analysis; Beehner et al. 2006b; Altmann et al. 2010).

We identified three significant terms in our model that reflected joint characteristics of the male and female of a given pair. First, we found a significant effect of the pairwise assortative mating index on consortship occurrence $(P<.001$; table 1; fig. 2$)$. The pairwise assortative mating index, which is a function of the value of and similarity between the hybrid scores for a given male and female, captures the strength of assortative mating between these two individuals (see "Material and Methods"). Thus, we found a strong indication that on average, baboons in Amboseli were more likely than expected by chance to consort assortatively, such that anubis-like individuals 
Table 1: Predictors of consortship behavior

\begin{tabular}{|c|c|c|c|c|}
\hline Explanatory variable $^{\mathrm{a}}$ & Tests for & Beta & $P^{\mathrm{b}}$ & Direction \\
\hline \multicolumn{5}{|l|}{ Genetic effects: } \\
\hline Male hybrid score & $\begin{array}{l}\text { Change in } \operatorname{Pr} \text { (consort) with male } \\
\text { yellow-anubis genetic } \\
\text { background }\end{array}$ & 4.335 & $<.001$ & $\begin{array}{l}\text { Higher male hybrid score leads to } \\
\text { higher } \operatorname{Pr}(\text { consort })\end{array}$ \\
\hline Female hybrid score & $\begin{array}{l}\text { Change in } \operatorname{Pr} \text { (consort) with female } \\
\text { yellow-anubis genetic background }\end{array}$ & .413 & .602 & $\ldots$ \\
\hline Pairwise assortative mating index & $\begin{array}{l}\text { Increase in } \operatorname{Pr} \text { (consort) when both } \\
\text { male and female had similar } \\
\text { yellow-anubis genetic } \\
\text { backgrounds }\end{array}$ & 1.459 & $<.001$ & $\begin{array}{l}\text { Higher assortative mating index } \\
\text { leads to higher } \operatorname{Pr} \text { (consort) }\end{array}$ \\
\hline Pairwise genetic distance ${ }^{c}$ & $\begin{array}{l}\text { Change in } \operatorname{Pr} \text { (consort) with greater } \\
\text { genetic distance between the } \\
\text { male and the female in a } \\
\text { potential consorting pair }\end{array}$ & -.657 & .004 & $\begin{array}{l}\text { Smaller genetic distance leads to } \\
\text { lower } \operatorname{Pr} \text { (consort) }\end{array}$ \\
\hline Pairwise genetic distance (transformed) & $\begin{array}{l}\text { Decreasing } \operatorname{Pr} \text { (consort) for pairs } \\
\text { with very low or very high } \\
\text { genetic distance }\end{array}$ & .9623 & .293 & $\cdots$ \\
\hline Male genetic diversity & $\begin{array}{l}\text { Change in } \operatorname{Pr} \text { (consort) with greater } \\
\text { male genetic diversity }\end{array}$ & 2.327 & .009 & $\begin{array}{l}\text { Higher male genetic diversity leads } \\
\text { to higher } \operatorname{Pr} \text { (consort) }\end{array}$ \\
\hline Female genetic diversity & $\begin{array}{l}\text { Change in } \operatorname{Pr} \text { (consort) with greater } \\
\text { female genetic diversity }\end{array}$ & -1.542 & .059 & $\ldots$ \\
\hline \multicolumn{5}{|l|}{ Dominance rank effects: } \\
\hline Male dominance rank & $\begin{array}{l}\text { Change in } \operatorname{Pr} \text { (consort) with higher } \\
\text { male rank, taking into account } \\
\text { number of males in the group }\end{array}$ & 3.418 & $<.001$ & $\begin{array}{l}\text { Higher male rank leads to higher } \\
\operatorname{Pr}(\text { consort })\end{array}$ \\
\hline Female dominance rank & $\begin{array}{l}\text { Change in } \operatorname{Pr} \text { (consort) with higher } \\
\text { female rank }\end{array}$ & .0371 & .207 & $\ldots$ \\
\hline Male-female rank interaction & $\begin{array}{l}\text { Change in } \operatorname{Pr} \text { (consort) when both } \\
\text { individuals were high ranking }\end{array}$ & -.00753 & $<.001$ & $\begin{array}{l}\text { Higher male and female rank leads } \\
\text { to higher } \operatorname{Pr} \text { (consort) }\end{array}$ \\
\hline \multicolumn{5}{|l|}{ Age and demographics: } \\
\hline Female age & $\begin{array}{l}\text { Change in } \operatorname{Pr} \text { (consort) with greater } \\
\text { female age }\end{array}$ & -.0594 & .025 & $\begin{array}{l}\text { Greater female age leads to lower } \\
\quad \operatorname{Pr}(\text { consort })\end{array}$ \\
\hline Female age (transformed) & $\begin{array}{l}\text { Increase in } \operatorname{Pr}(\text { consort) for middle- } \\
\text { aged females relative to young } \\
\text { and old females }\end{array}$ & .9634 & .065 & $\ldots$ \\
\hline Adult females present & $\begin{array}{l}\text { Change in } \operatorname{Pr} \text { (consort) when more } \\
\text { females were in the social group }\end{array}$ & -.0214 & .355 & $\ldots$ \\
\hline Adult males present & $\begin{array}{l}\text { Change in } \operatorname{Pr} \text { (consort) when more } \\
\text { males were in the social group }\end{array}$ & -.0452 & .098 & $\ldots$ \\
\hline \multicolumn{5}{|l|}{ Cycle properties: } \\
\hline Conceptive versus nonconceptive cycle & $\begin{array}{l}\text { Different } \operatorname{Pr} \text { (consort) between cycles } \\
\text { producing a pregnancy and cycles } \\
\text { that do not produce a pregnancy }\end{array}$ & .136 & .147 & $\ldots$ \\
\hline
\end{tabular}

Note: Bold type indicates variables for which $P<.01$.

a See "Material and Methods" for a full description of the variables. Effect sizes and significance reflect results from a joint analysis that included all parameters.

b Calculated from a comparison of beta values reported in this table with betas estimated from 1,000 permuted data sets.

c Genetic distance calculated using the Queller-Goodnight method for assessing relatedness (Queller and Goodnight 1989).

were more likely to consort with anubis-like individuals and yellow-like individuals were more likely to consort with yellow-like individuals. Second, we found a significant interaction between male and female dominance ranks. When both members of a pair of baboons were of high social dominance rank they were more likely to consort than when only one member of the pair was high ranking, and they were much more likely to consort than pairs in which both members were low ranking $(P<.001)$. Finally, in an extension of previous work on this population that demonstrated strong inbreeding avoidance, we observed a decreased probability of the occurrence of consortship with decreasing genetic distance between a potential pair $(P=.004)$. This suggests that individuals not only preferentially avoided close kin, as we have previously documented (Alberts and Altmann 1995; Alberts 1999), but also mated with more genetically distant partners in general. We observed no significant effect of cycle character- 
a)

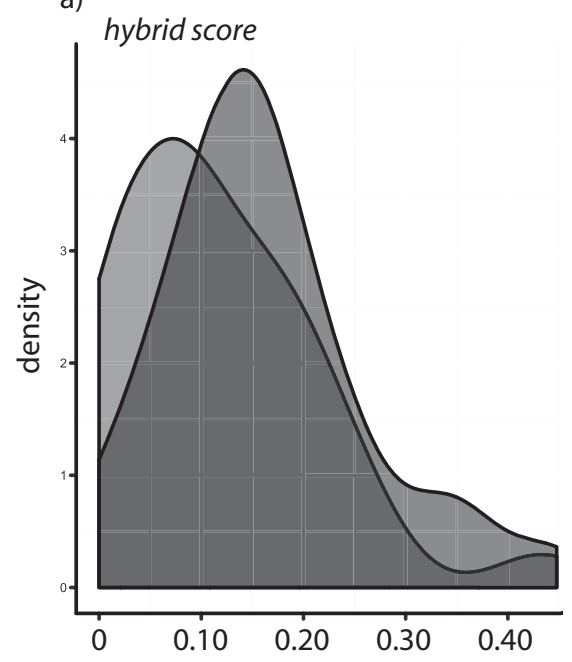

b)

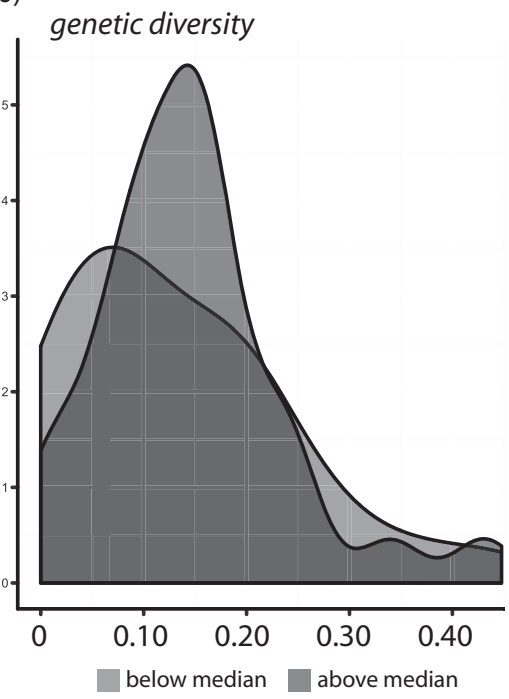

c)

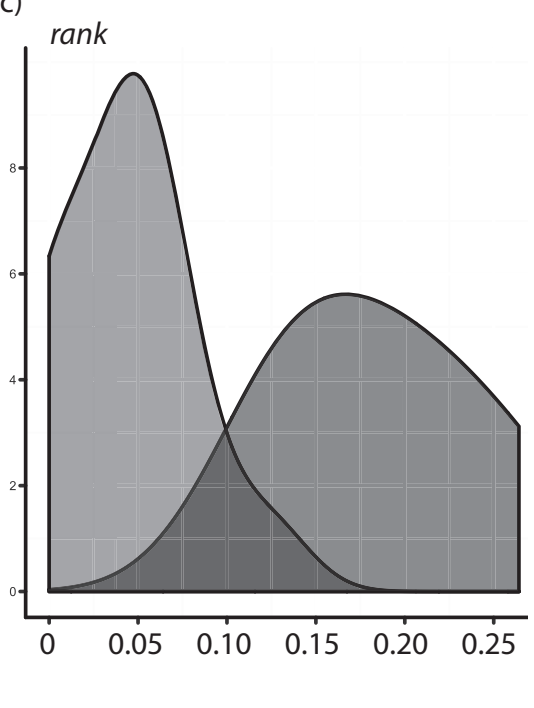

proportion of successful consortship opportunities

Figure 1: Male genetic background, genetic diversity, and dominance rank influenced consortship probabilities. Probability density functions for the proportion of consortship opportunities (see "Material and Methods") converted into successful consortships by each male ( $a$, $b$ ) or each male rank position $(c)$, where the male or rank position is the unit of analysis and summary values are from the raw data without controlling for other variables. Distributions are partitioned to represent two data sets, one including males above the median and one including males below the median for male hybrid score $(a)$, male genetic diversity $(b)$, or male rank $(c)$. Males with higher hybrid scores, higher genetic diversity, and higher dominance rank have a higher probability of consorting, given an opportunity, than other males.

istics (conceptive vs. nonconceptive; see "Material and Methods") or group demography in our model of consortship probabilities (table 1).

\section{Variance across Social Groups}

The predictors of mating behavior varied across social and demographic conditions. Specifically, we observed a substantial amount of intergroup heterogeneity in effect size and significance among the six most highly supported effects in the overall model (all of those identified in the overall model at $P \leq .01$; fig. 3 ). This variance across social and demographic conditions indicates that the predictors of mating behavior can be context dependent. Thus, our relatively large data set helped to both capture a mean effect size and characterize the stability of that effect across variable conditions.

Two of the male-specific effects we investigated, male hybrid score and male dominance rank, exhibited relatively consistent effects on consortship probabilities across social groups (fig. $3 a, 3 b$ ), suggesting that these two effects were generally robust to intergroup differences. Two of our joint male-female variables - the pairwise assortative mating index and the male-female rank interaction (fig. $3 c, 3 d$ ) -were also fairly robust, although they were more variable than male hybrid score and male dominance rank: effect sizes varied considerably across social groups but always fell in the same direction when significant (at a threshold of either $P \leq .01$, which we used for the full model, or $P \leq .05$, to account for the smaller data sets used in this analysis). Finally, in contrast to the four effects just described, the effects of pairwise genetic distance and male genetic diversity were different in different social groups (fig. $3 e, 3 f$ ). In particular, they fell in the opposite direction of the results for the full model for one or two social groups, respectively (at $P<.05$ ).

\section{Factors Predicting Consortship Occurrence}

Genetic effects and rank-related effects dominated the overall consortship model. To evaluate the relative importance of these effects, we used a leave- $k$-out strategy to evaluate how well either the significant genetic effects alone (genetic diversity and genetic background of potential consortship partners) or the significant rank-related effects alone predicted cases that were not used to fit the model.

We performed 100 iterations of the leave- $k$-out procedure (removing and attempting to predict the outcome of 500 of the total 12,141 data points in each case) and found 

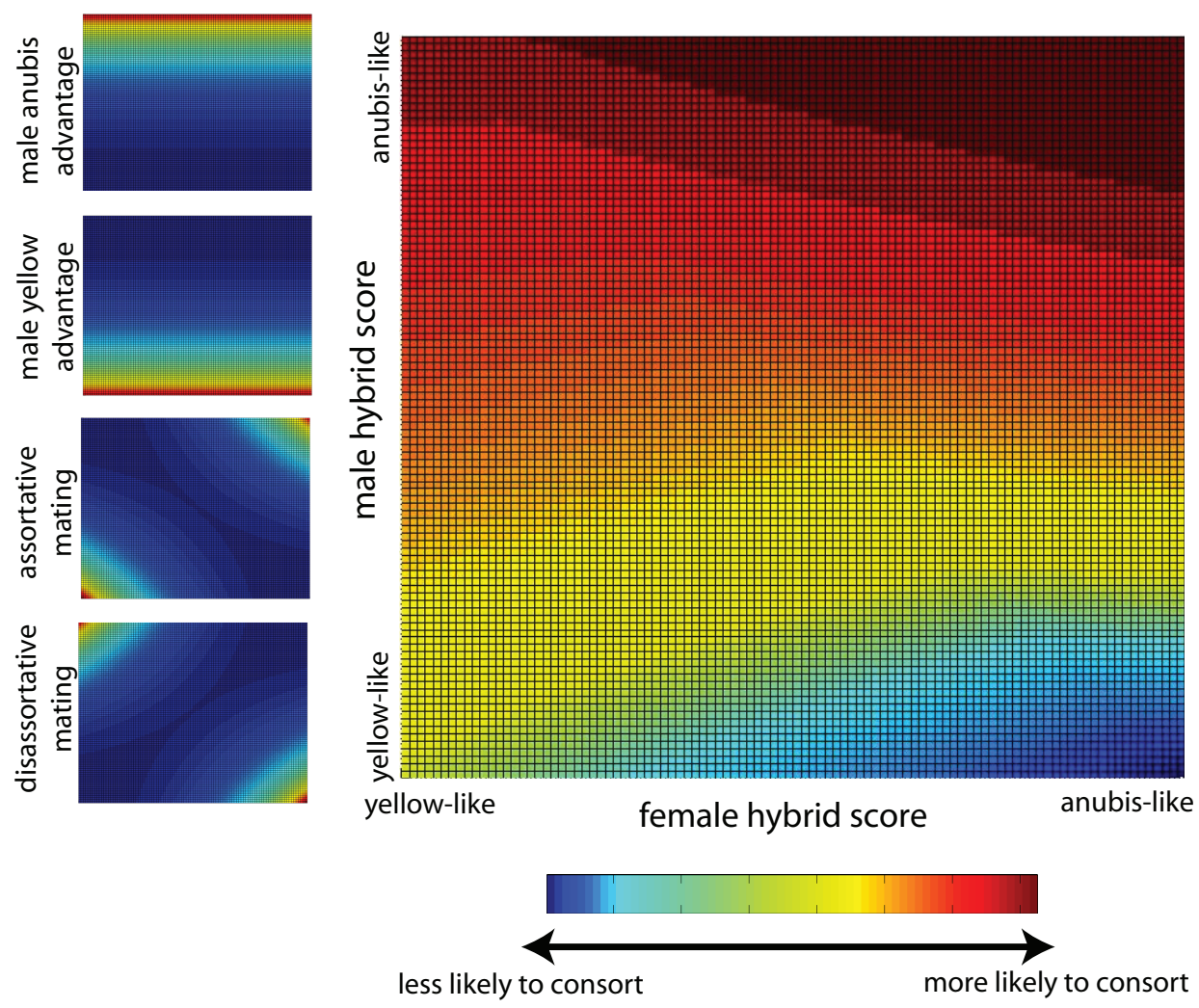

Figure 2: Assortative mating tendencies and male genetic background influenced consortship probabilities. The probability of a sexual consortship occurring increased with both male hybrid score and assortative pairings by hybrid score. The large central figure shows the relationship between female hybrid score, male hybrid score, and the probability of consortship on the basis of the fitted effects from the consortship model. Note that the fitted effects are a combination of two of the idealized results shown on the left: consortships were more likely to occur if the male was more anubis-like and also if both the male and the female had similar genetic backgrounds (assortative mating).

that both the set of significant genetic variables (male hybridity, male genetic diversity, pairwise genetic distance, and pairwise assortative mating index) and the set of significant rank-related variables (male rank and the interaction between male and female rank) predicted consortship outcomes better-than-random chance $(P<1 \times$ $10^{-16}$ for both genetic effects and rank effects; fig. 4). However, the rank-alone model had substantially better predictive power than the genetics-alone model. Mean AUC for the rank-alone model was $0.664( \pm 0.034 \mathrm{SD})$, compared with a mean AUC of $0.550( \pm 0.040 \mathrm{SD})$ for the genetics-alone model. Thus, although both sets of effects were significant predictors of consortship behavior, information about rank was a more valuable predictor than information about genetic background and diversity for any given pair of individuals (fig. 4).

\section{Assortative Mating Behavior}

The results of the full consortship model identified a previously unknown effect of admixture-based assortative mating on consortship behavior in baboons. This finding is of substantial interest: hybridization between baboon species appears to be common in the wild, and little evidence of hybrid dysgenesis has been reported in these species (Ackermann et al. 2006; Charpentier et al. 2008). However, the hybrid zones that have been identified along species boundaries appear to be narrow (Charpentier et al. 2012), and they could be constrained by behavioral or ecological differences between taxa. Therefore, we further examined the admixture-based assortative mating effect to identify whether particular individual characteristics were associated with a tendency to mate assortatively.

First, we asked whether the population-wide tendency 
a)

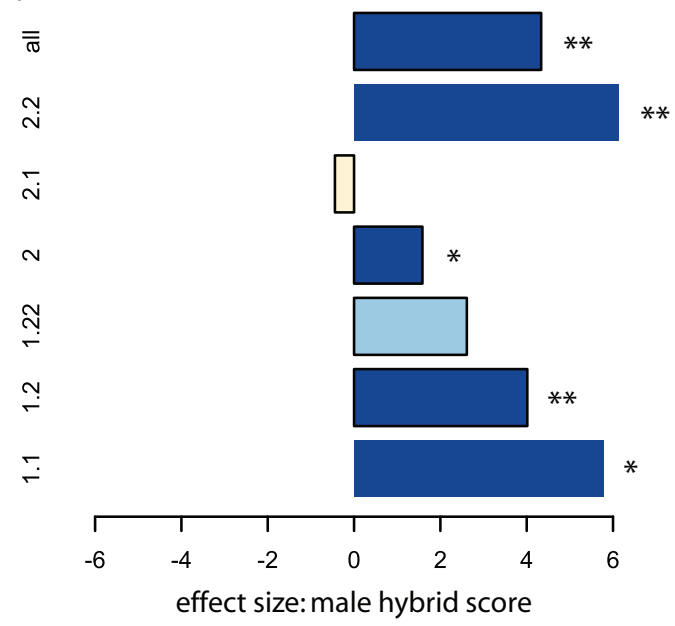

c)

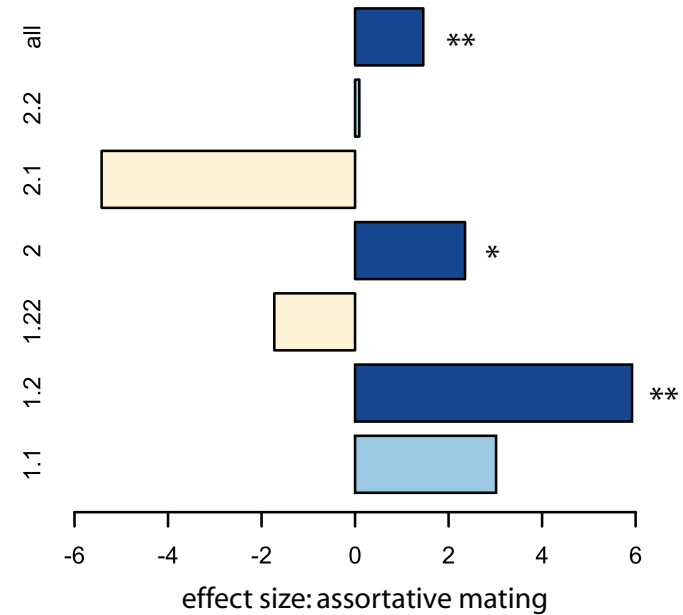

e)

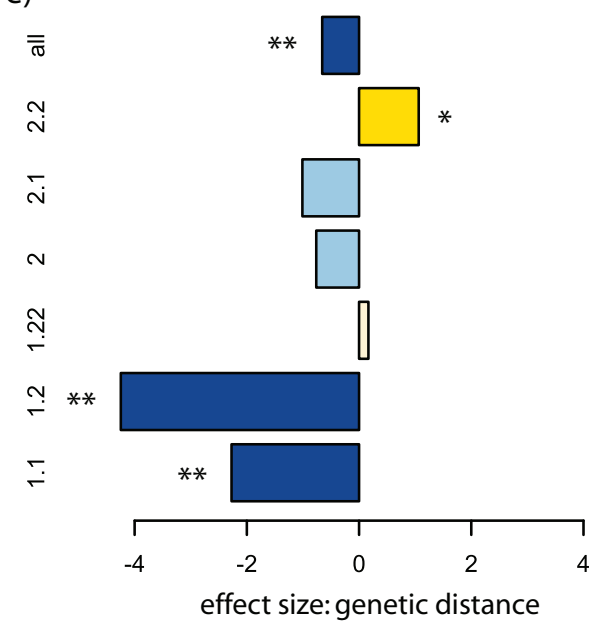

b)

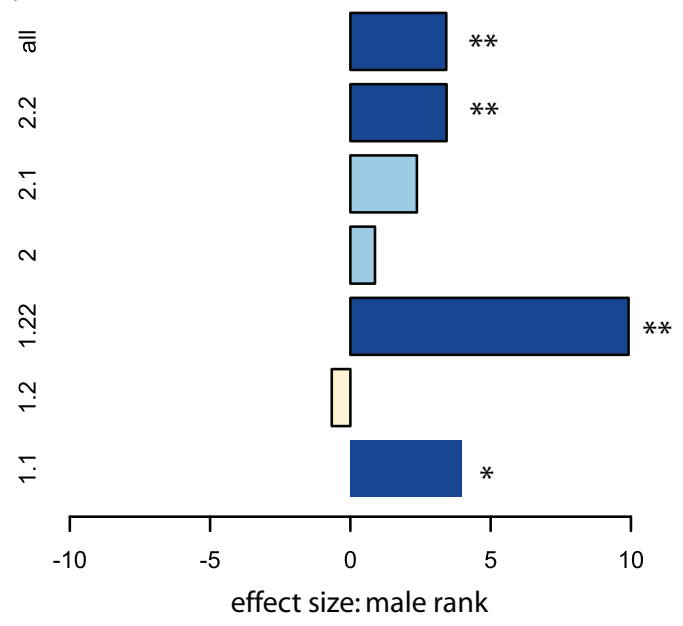

d)

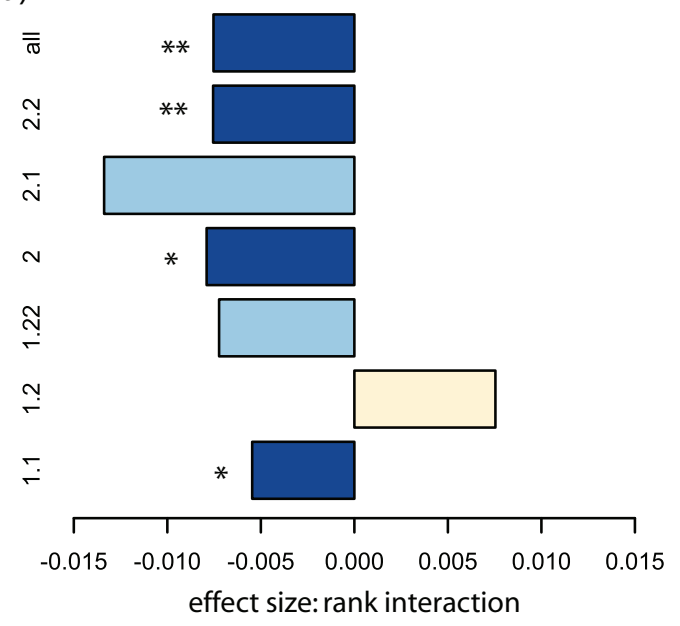

f)

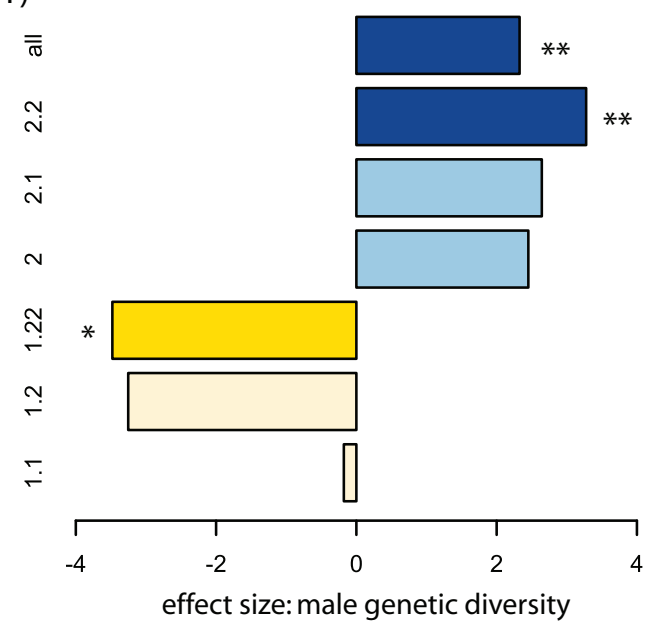


toward assortative mating was more reflective of patterns of mating behavior in males or in females (because both sexes mate with multiple partners, it is possible for assortative mating tendencies to be more common in one sex than the other). We identified a much stronger tendency for males than females to consort assortatively $\left(P=2.81 \times 10^{-4}\right)$. Indeed, we observed 10 males (of 88) that mated significantly more assortatively in our original data set than expected from 1,000 random permutations of the data set $(P<.01$ for each male). This represents many more assortatively mating males than the expected number (fewer than one male). In contrast, relatively fewer females ( $n=3$ of 95 ) mated more assortatively than expected by chance, and a number of females actually tended to mate more disassortatively than expected by chance. This disassortative mating by females may be linked to another result in our analysis, namely, the fact that males with higher hybrid scores (more anubis-like males) obtained more consortships. Because most females in the data set were yellow baboons (fig. A1), a mating advantage for more anubis-like males results in disassortative mating for some females.

Second, we observed no relationship, for males or females, between the tendency to mate assortatively and an individual's own hybrid score (males: $P=.224$; females: $P=.160$; across both sexes: $P=.414$ ). Thus, individuals with higher and lower hybrid scores (anubis-like individuals and yellow-like individuals) both contributed to the tendency to mate assortatively in Amboseli.

\section{Discussion}

\section{Genetic Influences on Mating Success and Partner Choice}

Genetic effects played a significant role in shaping patterns of mating behavior in the natural population of social mammals we studied. These genetic effects went beyond individual genetic diversity and genetic distance between partners, which have been described elsewhere (e.g., in relation to inbreeding avoidance [Alberts and Altmann 1995; Pusey and Wolf 1996] or as a correlate of male competitive advantage [Latter and Sved 1994; Eklund 1996; Meagher et al. 2000; Tiira et al. 2003; reviewed in Kempenaers 2007]). Here we also identified novel effects of admixture-related genetic background. Specifically, we observed an advantage for more anubis-like males in gaining consortships and a pattern of assortative mating by genetic background. Consortships were most likely to occur when the male in a potential pairing was anubis-like and his female partner was also anubis-like, and they were least likely to occur when the male in the pair was yellowlike and his female partner was anubis-like.

The effects of admixture-related genetic background in our data set primarily reflected male mating patterns: male admixture proportions influenced the probability of consortship occurrence, but female admixture proportions did not. This result echoes previous analyses in this population, in which we documented a stronger effect of admixture on age at maturity in males than in females. In the case of age at maturity, we argued that maternal effects, which played a more important role in females than in males, muted the effects of admixture in females relative to males (Charpentier et al. 2008). In the case of mating success, the male-female difference may be partly attributable to the lower variance in mating success among females than males, which is the common pattern in most animal species (Trivers 1972; Andersson 1994). Postadolescent females generally mate during every sexual cycle, whereas male mating success is strongly skewed; this pattern is reinforced by the strong dominance rank hierarchy in this species (Alberts et al. 2003). The greater variance in male mating success relative to that of females sets the stage for any genetic background effects to be stronger in males than in females.

Such a result naturally prompts the question of the mechanism by which anubis-like males developed this advantage. A careful analysis of a mechanism is beyond the scope of this analysis, but the results presented here suggest several hypotheses, all of which involve existing reproductive strategies in both yellow and anubis social groups. For instance, more anubis-like males may be better able to monopolize reproductive females because they employ more effective behavioral mating strategies (e.g., they may be more effective at coalition formation, better able to exclude competitors through higher rates of aggression in the context of mating, or more successful at coercing females). More anubis-like males may also experience rankmediated advantages that were not completely accounted

Figure 3: Size and significance of effects varied across social groups. The six variables identified as significant predictors of consortship occurrence in the overall analysis were investigated in five social groups (excluding the two groups with the smallest available sample size): male hybrid score $(a)$, male dominance rank $(b)$, assortative mating index $(c)$, male-female dominance rank interaction $(d)$, genetic distance $(e)$, and male genetic diversity $(f)$. Colors indicate strength of agreement with the effect identified in the combined analysis across all groups: dark blue represents a significant effect that is concordant with the direction of the effect in the full analysis, light blue presents a nonsignificant effect that is concordant with the direction of the effect in the full analysis, light yellow represents a nonsignificant effect in the opposite direction of the effect in the full analysis, and dark yellow represents a significant effect in the opposite direction of the effect in the full analysis. One asterisk indicates $P \leq .01$; two asterisks indicate $P \leq .05$. 


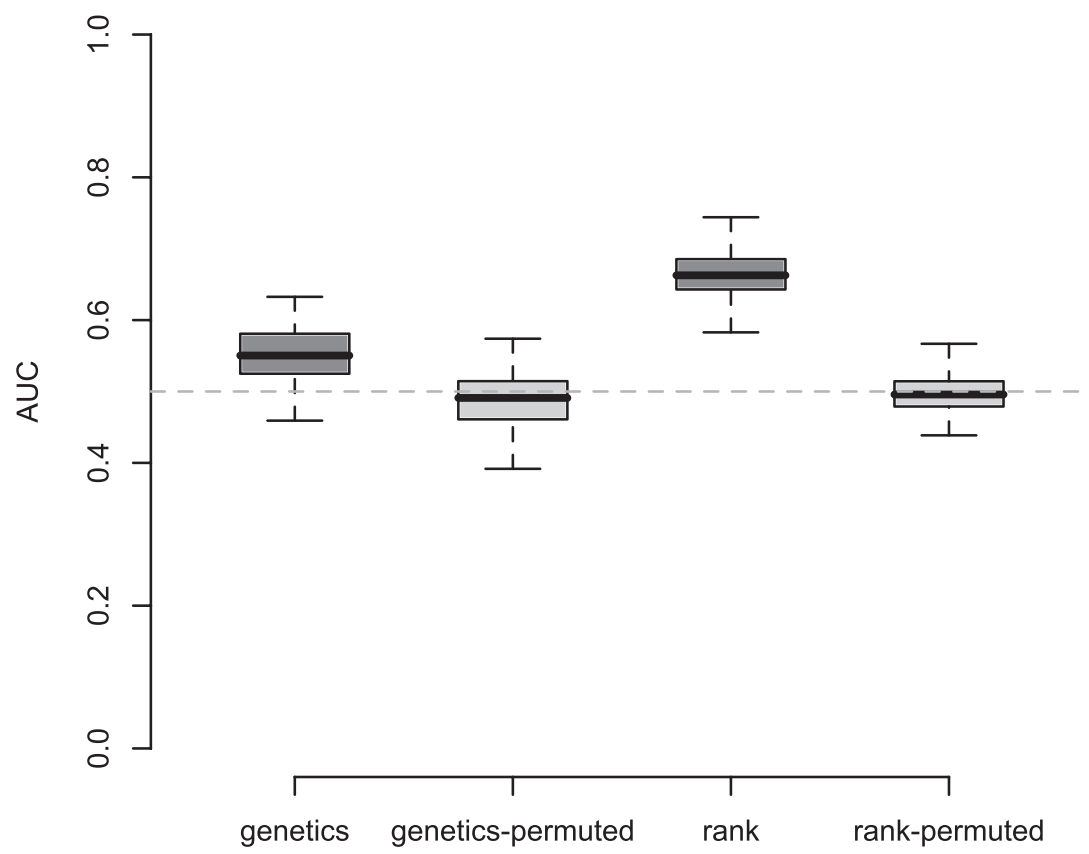

Figure 4: Rank-related effects and genetic effects predicted consortship behavior. Genetic variables and rank-related variables both improved prediction of consortship outcomes over random chance, but rank-related variables performed better. When the data set was permuted, neither set of variables exhibited improved prediction performance over random chance, as expected (area under the curve [AUC] $=0.5$, indicated by the dashed gray line). Boxplots show the distribution of AUC values for 100 iterations of leave- $k$-out model fitting and prediction, where $k=500$ possible consortship pairs.

for by our model. Alternatively, or in addition, females may actively prefer more anubis-like males and may therefore preferentially facilitate consortship pairings with them. Indeed, female mate choice (as indicated by active maintenance of proximity to preferred males, avoidance of unpreferred males, and directed proceptive behavior during estrus) has been documented in baboons (Seyfarth 1978; Bercovitch 1991, 1995), and in Amboseli it has been hypothesized to play a role in observed departures from rank-based priority-of-access models (Alberts et al. 2003). Bercovitch (1995) suggested, however, that male reproductive strategies are more predictive of mating behavior than female choice overall. These findings motivate an analysis of the joint and relative contributions of malebiased and female-biased strategies in future work.

Understanding the proximate mechanisms underlying the observed assortative mating effect also represents a challenge. Because our data set encompassed several generations of admixture, assortative mating preferences were unlikely to be fully explained by a simple mechanism of learning from a parent: anubis genetic material could be inherited maternally, paternally, or through both lines. An alternative possibility is that genetic loci for assortative mating preferences may segregate in yellow baboon and anubis baboon populations (as in Heliconius butterflies; Kronforst et al. 2006). Indeed, the emergence of genetically based assortative mating preferences often accompanies the early stages of divergence between two taxa (Coyne and Orr 2004), which probably aptly describes the situation for yellow baboons and anubis baboons.

\section{Evolutionary Implications of Genetic Effects on Mating Behavior}

A corollary of the presence of genetic effects on mating behavior is the potential for these effects to exert evolutionary genetic change. Indeed, the two novel genetic effects we identified (an advantage to males with a more anubis-like genetic background and assortative mating by genetic background) both relate to hybridization and admixture, a phenomenon that is relatively recent in this population (Samuels and Altmann 1986; Alberts and Altmann 2001) and that has been hypothesized to be part of evolutionary changes that may be in progress for baboons in East Africa as a whole (Jolly 2001; Jolly et al. 2011). Specifically, it has been suggested that Amboseli falls at the wave front of a range expansion by anubis baboons into the historical range of yellow baboons. Phylogeo- 
graphic studies of baboon mitochondrial DNA variation across Africa provide support for historical introgression of this kind elsewhere (Zinner et al. 2009, 2011; Keller et al. 2010; Jolly et al. 2011). In particular, mitochondrial DNA haplotypes exhibit widespread paraphyly with respect to phenotypically based taxonomic designations. This pattern has been proposed to result from "nuclear swamping": asymmetric introgression of one taxon into a sister taxon, mediated by hybridization events in which hybridizing males consistently originate from the expanding taxon and hybridizing females consistently originate from the retreating group (Jolly 1993; Zinner et al. 2009; Keller et al. 2010; Jolly et al. 2011).

Such a mechanism assumes that males from the expanding group will regularly outcompete native males after immigrating into social groups composed, at least at the outset of this process, primarily of members of a divergent group. In the case of Amboseli, the mechanism therefore predicts that male anubis immigrants and their anubislike male offspring will experience better-than-expected success in mating with yellow baboon females. Our results provide direct evidence in favor of this hypothesis. Increased proportion of anubis ancestry in males was directly correlated with increased success in competing for consortships. This effect likely accounts, at least in part, for the rapid increase in the number of hybrid individuals in the Amboseli population over the past several decades (Tung et al. 2008). Our previous results indicate that hybrid males also tend to mature more rapidly than their yellow male counterparts (Charpentier et al. 2008). Taken together, these findings imply that anubis ancestry contributes to a selectively advantageous syndrome of traits in Amboseli that is supportive of male-mediated range expansion by anubis baboons into a previously yellow baboon-inhabited range in Kenya.

At the same time, the assortative mating pattern we identified represents, to our knowledge, the first report of any potential isolating barrier between anubis baboons and yellow baboons, which hybridize readily in captivity as well as in natural boundary zones (Maples and McKern 1967; Samuels and Altmann 1986; Ackermann et al. 2006). While the reproductive advantage enjoyed by anubis males in Amboseli should promote the spread of the anubis genetic background, the assortative mating effect should slow this effect by directing matings among anubis-like males toward more anubis-like females instead of toward yellow females. The indications of assortative mating in our analysis echo previous findings on mating behavior between anubis baboons and hamadryas baboons (Papio hamadryas) in the Awash National Park of Ethiopia, where phenotypically similar males and females in some social groups have sometimes been reported to preferentially pair (Bergman and Beehner 2003; Beehner and Bergman 2006; but see Bergman et al. 2008). However, while the social structures of anubis baboons and hamadryas baboons differ substantially (Kummer 1968) and may thus explain assortative mating patterns in Awash, the anubis baboon and yellow baboon social structures are too similar to account for the assortative mating effect we observe in Amboseli (e.g., cf. accounts in Hausfater 1975 and Alberts et al. 2003 on yellow baboons with those in Bercovitch 1991 and Smuts 1985 on anubis baboons). Assortative preferences in yellow and anubis baboons may therefore have arisen in conjunction with other, non-social-structure-related changes such as ecological adaptation, in the years since these taxa originally diverged. However, at this early stage in yellow-anubis divergence, expression of these preferences is clearly incomplete.

\section{Genetic Effects in a Socially Complex Context}

Our results strongly emphasize the need for genetic effects to be evaluated alongside social and demographic effects on mating behavior within socially complex species. Two points in particular are worth emphasizing.

First, although our results provide strong support for the existence of genetic effects on consortship behavior, we identified substantial variance in their effect sizes across different social and demographic conditions. Indeed, the magnitude of every predictor we tested differed across the six groups we analyzed individually. This result has previously been described for male dominance rank (Cowlishaw and Dunbar 1991; Bulger 1993; Altmann and Alberts $2003 \mathrm{~b}$ ) but not for multiple coacting predictors of mating behavior within a population. It thus highlights the central importance of social and demographic context for understanding genetic effects on mating behavior. Interestingly, while male hybrid score had the most consistent effect on consortship behavior outside of male dominance rank, the assortative mating effect was more variable across social groups. Unlike male genetic background effects, assortative mating requires that specific pairwise combinations of individuals be present in a group. On the basis of first principles, assortative mating is therefore likely to be more sensitive to demographic context (such as small group size [group size ranged from 9 to 48 adults in these social groups], age structure, and group membership; see also Alberts and Altmann 1995; Alberts et al. 2003; Altmann and Alberts 2003a; Charpentier et al. 2008). Demographic effects on mating patterns represent an intriguing direction for future study.

Second, our results indicate that although genetic effects had an important influence on mating outcomes within Amboseli, male dominance rank was a better overall predictor of consortship occurrence. The likely explanation for this observation is that while genetic factors differ- 
entiate individuals competing for a consortship opportunity in some cases-when genetic factors vary greatly within social groups-differences in social status always differentiate competing individuals. It may be possible for all adult males in a social group to be highly genetically diverse, share similar levels of admixture, and have no close kin relationships with fertile females in the same group. However, it will never be possible for all adult males in a social group to be high ranking. In general, rank will therefore be a more robust predictor of consortship opportunities than effects in which within-group variation will sometimes be low, including all genetic effects. This result highlights a key difference between assessing genetic effects on mating in highly complex, socially hierarchical species and doing so in species in which social structures are fluid, less developed, or absent altogether.

Taken together, our results emphasize the importance of behavioral plasticity and social interactions in mediating genetic effects. Many animal species exhibit pronounced behavioral plasticity and complex social interactions, including variation in social status as described here. These phenomena may modify genetic effects in a wide variety of ways that have not yet been studied. We suggest an interesting parallel with maternal effects, which have become the focus of much interest in the past 2 decades because they can moderate or even swamp genetic effects, with important consequences for evolution (Maestripieri and Mateo 2009). Our results support a similar role for behavioral plasticity and social interactions in moderating genetic effects on reproductive success.

\section{Acknowledgments}

This work was supported by the National Science Foundation (IOS-0919200) and the National Institute of Aging (NIA R01AG034513-01 and NIA P01-AG031719, to S.C.A.), the Princeton Aging Center (P30 AG024361, to J.A.), a Marie Curie International Reintegration Grant (HYBRIDBAB; 239301, to M.J.E.C.), and a University of Chicago Fellows postdoctoral fellowship (to J.T.). We thank the Office of the President, Republic of Kenya; the Kenya Wildlife Service and its Amboseli staff and wardens; our local sponsor, the Institute for Primate Research; the National Museums of Kenya; and the members of the Amboseli-Longido pastoralist communities. Particular thanks go the Amboseli field-workers who contributed to genetic and environmental sampling, especially R. Mututua, S. Sayialel, P. Titen, and K. Warutere. T. Wango provided assistance with the samples and logistical support in Nairobi. Three anonymous reviewers provided helpful comments and constructive criticism during the development of this manuscript. Data included in this study were obtained in accordance with Institutional Animal Care and Use Committee protocols approved by Duke University (A0840903) and Princeton University (1689).

\section{Literature Cited}

Ackermann, R. R., J. Rogers, and J. M. Cheverud. 2006. Identifying the morphological signatures of hybridization in primate and human evolution. Journal of Human Evolution 51:632-645.

Alberts, S. C. 1999. Paternal kin discrimination in wild baboons. Proceedings of the Royal Society B: Biological Sciences 266:15011506.

Alberts, S. C., and J. Altmann. 1995. Balancing costs and opportunities: dispersal in male baboons. American Naturalist 145:279306 .

-2001. Immigration and hybridization patterns of yellow and anubis baboons in and around Amboseli, Kenya. American Journal of Primatology 53:139-154.

2003. Matrix models for primate life history analysis. Pages 66-102 in P. Kappeler and M. Pereira, eds. Primate life histories and socioecology. University of Chicago Press, Chicago.

Alberts, S. C., J. Altmann, and M. L. Wilson. 1996. Mate guarding constrains foraging activity of male baboons. Animal Behaviour 51:1269-1277.

Alberts, S. C., J. C. Buchan, and J. Altmann. 2006. Sexual selection in wild baboons: from mating opportunities to paternity success. Animal Behaviour 72:1177-1196.

Alberts, S. C., H. E. Watts, and J. Altmann. 2003. Queuing and queuejumping: long-term patterns of reproductive skew in male savannah baboons, Papio cynocephalus. Animal Behaviour 65:821-840.

Altmann, J. 1974. Observational study of behavior: sampling methods. Behaviour 49:227-267.

1980. Baboon mothers and infants. Harvard University Press, Cambridge, MA.

Altmann, J., and S. C. Alberts. 2003a. Intraspecific variability in fertility and offspring survival in a non-human primate: behavioral control of ecological and social sources. Pages 140-169 in K. W. Wachter and R. A. Bulatao, eds. Offspring: the biodemography of fertility and family behavior. National Academy Press, Washington, DC.

. $2003 b$. Variability in reproductive success viewed from a lifehistory perspective in baboons. American Journal of Human Biology 15:401-409.

. 2005. Growth rates in a wild primate population: ecological influences and maternal effects. Behavioral Ecology and Sociobiology 57:490-501.

Altmann, J., S. C. Alberts, S. A. Haines, J. Dubach, P. Muruthi, T. Coote, E. Geffen, et al. 1996. Behavior predicts genetic structure in a wild primate group. Proceedings of the National Academy of Sciences of the USA 93:5797-5801.

Altmann, J., L. Gesquiere, J. Galbany, P. O. Onyango, and S. C. Alberts. 2010. Life history context of reproductive aging in a wild primate model. Annals of the New York Academy of Sciences 1204: 127-138.

Altmann, J., G. Hausfater, and S. A. Altmann. 1988. Determinants of reproductive success in savannah baboons Papio cynocephalus. Pages 403-418 in T. H. Clutton-Brock, ed. Reproductive success. University of Chicago Press, Chicago. 
Andersson, M. 1994. Sexual selection. Princeton University Press, Princeton, NJ.

Barton, R. A. 1993. Sociospatial mechanisms of feeding competition in female olive baboons, Papio anubis. Animal Behaviour 46:791802.

Barton, R. A., and A. Whiten. 1993. Feeding competition among female olive baboons, Papio anubis. Animal Behaviour 46:777789.

Beehner, J. C., and T. J. Bergman. 2006. Female behavioral strategies of hybrid baboons in the Awash National Park, Ethiopia. Pages 53-79 in L. Swedell and S. Leigh, eds. Reproduction and fitness in baboons: behavioral, ecological, and life history perspectives. Springer, New York.

Beehner, J. C., N. Nguyen, E. O. Wango, S. C. Alberts, and J. Altmann. $2006 a$. The endocrinology of pregnancy and fetal loss in wild baboons. Hormones and Behavior 49:688-699.

Beehner, J. C., D. A. Onderdonk, S. C. Alberts, and J. Altmann. $2006 \mathrm{~b}$. The ecology of conception and pregnancy failure in wild baboons. Behavioral Ecology 17:741-750.

Bercovitch, F. B. 1991. Mate selection, consortship formation, and reproductive tactics in adult female savanna baboons. Primates 32: $437-452$.

- 1995. Female cooperation, consortship maintenance, and male mating success in savanna baboons. Animal Behaviour 50: 137-149.

Bergman, T. J., and J. C. Beehner. 2003. Hybrid zones and sexual selection: insights from the Awash baboon hybrid zone (Papio hamadryas anubis $\times$ P. h. hamadryas). Pages 500-537 in C. Jones, ed. Sexual selection and primates: new insights and directions. American Society of Primatologists, Norman, OK.

Bergman, T. J., J. E. Phillips-Conroy, and C. J. Jolly. 2008. Behavioral variation and reproductive success of male baboons (Papio anubis $\mathrm{x}$ Papio hamadryas) in a hybrid social group. American Journal of Primatology 70:136-147.

Boughman, J. W. 2001. Divergent sexual selection enhances reproductive isolation in sticklebacks. Nature 411:944-948.

Buchan, J. C., S. C. Alberts, J. B. Silk, and J. Altmann. 2003. True paternal care in a multi-male primate society. Nature 425:179181.

Bulger, J. B., and W. J. Hamilton. 1987. Rank and density correlates of inclusive fitness measures in a natural chacma baboon (Papio ursinus) population. International Journal of Primatology 8:635650.

Bulger, J. G. 1993. Dominance rank and access to estrous females in male savanna baboons. Behaviour 127:67-103.

Chapman, T., G. Arnqvist, J. Bangham, and L. Rowe. 2003. Sexual conflict. Trends in Ecology \& Evolution 18:41-47.

Charpentier, M. J. E., M. C. Fontaine, E. Cherel, J. P. Renoult, T. Jenkins, L. Benoit, N. Barthes, et al. 2012. Genetic structure in a dynamic baboon hybrid zone corroborates behavioral observations in a hybrid population. Molecular Ecology 21:715-731.

Charpentier, M. J. E., J. Tung, J. Altmann, and S. C. Alberts. 2008. Age at maturity in wild baboons: genetic, environmental and demographic influences. Molecular Ecology 17:2026-2040.

Clutton-Brock, T. H. 1989. Review lecture: mammalian mating systems. Proceedings of the Royal Society B: Biological Sciences 236: 339-372.

Clutton-Brock, T. H., K. E. Rose, and F. E. Guinness. 1997. Densityrelated changes in sexual selection in red deer. Proceedings of the Royal Society B: Biological Sciences 264:1509-1516.
Coltman, D. W., J. A. Smith, D. R. Bancroft, J. Pilkington, A. D. C. MacColl, T. H. Clutton-Brock, and J. M. Pemberton. 1999. Density-dependent variation in lifetime breeding success and natural and sexual selection in Soay rams. American Naturalist 154:730746.

Cowlishaw, G., and R. I. M. Dunbar. 1991. Dominance rank and mating success in male primates. Animal Behaviour 41:1045-1056.

Coyne, J. A., and H. A. Orr. 2004. Speciation. Sinauer, Sunderland, MA.

Eklund, A. 1996. The effects of inbreeding on aggression in wild male house mice (Mus domesticus). Behaviour 133:883-901.

Ellis, L. 1995. Dominance and reproductive success among nonhuman animals: a cross-species comparison. Ethology and Sociobiology 16:257-333.

Gavrilets, S., G. Arnqvist, and U. Friberg. 2001. The evolution of female mate choice by sexual conflict. Proceedings of the Royal Society B: Biological Sciences 268:531-539.

Gesquiere, L. R., E. O. Wango, S. C. Alberts, and J. Altmann. 2007. Mechanisms of sexual selection: sexual swellings and estrogen concentrations as fertility indicators and cues for male consort decisions in wild baboons. Hormones and Behavior 51:114-125.

Haesler, M. P., and O. Seehausen. 2005. Inheritance of female mating preference in a sympatric sibling species pair of Lake Victoria cichlids: implications for speciation. Proceedings of the Royal Society B: Biological Sciences 272:237-245.

Halliday, T. 1988. Sexual conflict and female choice in fishes. Trends in Ecology \& Evolution 3:124-125.

Hausfater, G. 1975. Dominance and reproduction in baboons (Papio cynocephalus): quantitative analysis. Contributions to Primatology $7: 2-150$.

Hettyey, A., G. Hegyi, M. Puurtinen, H. Hoi, J. Török, and D. J. Penn. 2010. Mate choice for genetic benefits: time to put the pieces together. Ethology 116:1-9.

Jennions, M. D., and M. Petrie. 2000. Why do females mate multiply? a review of the genetic benefits. Biological Reviews 75:21-64.

Jolly, C. J. 1993. Species, subspecies and baboon systematics. Pages 67-107 in W. Kimbel and L. Martin, eds. Species, species concepts and primate evolution. Wiley, New York.

- 2001. A proper study for mankind: analogies from the papionin monkeys and their implications for human evolution. Yearbook of Physical Anthropology 44:177-204.

Jolly, C. J., A. S. Burrell, J. E. Phillips-Conroy, C. Bergey, and J. Rogers. 2011. Kinda baboons (Papio kindae) and grayfoot chacma baboons ( $P$. ursinus griseipes) hybridize in the Kafue river valley, Zambia. American Journal of Primatology 73:291-303.

Keller, C., C. Roos, L. F. Groeneveld, J. Fischer, and D. Zinner. 2010. Introgressive hybridization in southern African baboons shapes patterns of mtDNA variation. American Journal of Physical Anthropology 142:125-136.

Kempenaers, B. 2007. Mate choice and genetic quality: a review of the heterozygosity theory. Advances in the Study of Behavior 37: 189-278.

Kronforst, M. R., L. G. Young, D. D. Kapan, C. McNeely, R. J. O’Neill, and L. E. Gilbert. 2006. Linkage of butterfly mate preference and wing color preference cue at the genomic location of wingless. Proceedings of the National Academy of Sciences of the USA 103: 6575-6580.

Kummer, H. 1968, Social organization of hamadryas baboon: a field study. Karger, Basel.

Latter, B. D. H., and J. A. Sved. 1994. A re-evaluation of data from 
competitive tests shows high levels of heterosis in Drosophila melanogaster. Genetics 137:509-511.

Maestripieri, D., and J. M. Mateo. 2009. Maternal effects in mammals. University of Chicago Press, Chicago.

Maples, W., and T. McKern. 1967. A preliminary report on classification of the Kenya baboon. Pages 13-22 in H. Vagtborg, ed. The baboon in medical research. University of Texas Press, Austin.

Mávarez, J., C. A. Salazar, E. Bermingham, C. Salcedo, C. D. Jiggins, and M. Linares. 2006. Speciation by hybridization in Heliconius butterflies. Nature 441:868-871.

Meagher, S., D. J. Penn, and W. K. Potts. 2000. Male-male competition magnifies inbreeding depression in wild house mice. Proceedings of the National Academy of Sciences of the USA 97:33243329.

Melnick, D. J., and M. C. Pearl. 1987. Cercopithecines in multimale groups: genetic diversity and population structure. Pages 121-134 in B. B. Smuts, D. L. Cheney, R. Seyfarth, R. W. Wrangham, and T. T. Struhsaker, eds. Primate societies. University of Chicago Press, Chicago.

Muller, M. N., M. E. Thompson, and R. W. Wrangham. 2006. Male chimpanzees prefer mating with old females. Current Biology 16: 2234-2238.

Neff, B. D., and T. E. Pitcher. 2005. Genetic quality and sexual selection: an integrated framework for good genes and compatible genes. Molecular Ecology 14:19-38.

2008. Mate choice for non-additive genetic benefits: a resolution to the lek paradox. Journal of Theoretical Biology 254: 147-155.

Newman, T. K., C. J. Jolly, and J. Rogers. 2004. Mitochondrial phylogeny and systematics of baboons (Papio). American Journal of Physical Anthropology 124:17-27.

Partridge, L. 1983. Non-random mating and offspring fitness. Pages 227-255 in P. Bateson, ed. Mate choice. Cambridge University Press, Cambridge.

Petrie, M., T. Halliday, and C. Sanders. 1991. Peahens prefer peacocks with more elaborate trains. Animal Behaviour 41:323-331.

Pfennig, K. S. 2007. Facultative mate choice drives adaptive hybridization. Science 318:965-967.

Pinc, K. O., J. Altmann, and S. C. Alberts. 2009. BABASE: technical specifications for the Amboseli Baboon Project data management system. http://papio.biology.duke.edu/babase_system.html.

Pusey, A., and M. Wolf. 1996. Inbreeding avoidance in animals. Trends in Ecology \& Evolution 11:201-206.

Queller, D., and K. Goodnight. 1989. Estimating relatedness using genetic markers. Evolution 43:258-275.

Samuels, A., and J. Altmann. 1986. Immigration of a Papio anubis male into a group of Papio cynocephalus baboons and evidence for an anubis-cynocephalus hybrid zone in Amboseli, Kenya. International Journal of Primatology 7:131-138.

Seehausen, O., and D. Schluter. 2004. Male-male competition and nuptial-colour displacement as a diversifying force in Lake Victoria cichlid fishes. Proceedings of the Royal Society B: Biological Sciences 271:1345-1353.
Seyfarth, R. M. 1978. Social relationships among adult male and female baboons. 1. Behavior during sexual consortship. Behaviour 64:205-226.

Smuts, B. B. 1985. Sex and friendship in baboons. Aldine de Gruyter, New York.

1987. Sexual competition and mate choice. Pages 385-412 in B. B. Smuts, D. L. Cheney, R. M. Seyfarth, R. W. Wrangham, and T. T. Struhsaker, eds. Primate societies. University of Chicago Press, Chicago.

Smuts, B. B., D. L. Cheney, R. M. Seyfarth, R. W. Wrangham, and T. T. Struhsaker. 1987. Primate societies. University of Chicago Press, Chicago.

Tiira, K., A. Laurila, N. Peuhkuri, J. Piironen, E. Ranta, and C. R. Primmer. 2003. Aggressiveness is associated with genetic diversity in landlocked salmon (Salmo salar). Molecular Ecology 12:23992407.

Tregenza, T., and N. Wedell. 2000. Genetic compatibility, mate choice and patterns of parentage: invited review. Molecular Ecology 9: 1013-1027.

Trivers, R. L. 1972. Paternal investment and sexual selection. Pages 136-179 in B. Campbell, ed. Sexual selection and the descent of man 1871-1971. Aldine, Chicago.

Tung, J., M. J. E. Charpentier, D. A. Garfield, J. Altmann, and S. C. Alberts. 2008. Genetic evidence reveals temporal change in hybridization patterns in a wild baboon population. Molecular Ecology 17:1998-2011.

Van Horn, R. C., J. C. Buchan, J. Altmann, and S. Alberts. 2007. Divided destinies: group choice by female savannah baboons during social group fission. Behavioral Ecology and Sociobiology 61: 1823-1837.

Veen, T., T. Borge, S. C. Griffith, G.-P. Saetre, S. Bures, L. Gustafsson, and B. C. Sheldon. 2001. Hybridization and adaptive mate choice in flycatchers. Nature 411:45-50.

Weingrill, T., J. E. Lycett, L. Barrett, R. A. Hill, and S. P. Henzi. 2003. Male consortship behaviour in chacma baboons: the role of demographic factors and female conceptive probabilities. Behaviour 140:405-427.

Weingrill, T., J. E. Lycett, and S. P. Henzi. 2000. Consortship and mating success in chacma baboons (Papio cynocephalus ursinus). Ethology 106:1033-1044.

Wildt, D. E., L. L. Doyle, S. C. Stone, and R. M. Harrison. 1977. Correlation of perineal swelling with serum ovarian hormone levels, vaginal cytology, and ovarian follicular development during the baboon reproductive cycle. Primates 18:261-270.

Zinner, D., U. Buba, S. Nash, and C. Roos. 2011. Pan-African voyagers: the phylogeography of baboons. Pages 267-306 in V. Sommer and C. Ross, eds. Primates of Gashaka. Developments in Primatology: Progress and Prospects. Springer, New York.

Zinner, D., L. F. Groeneveld, C. Keller, and C. Roos. 2009. Mitochondrial phylogeography of baboons (Papio spp.): indication for introgressive hybridization? BMC Evolutionary Biology 9:83.

Associate Editor: Suzanne Henson Alonzo Editor: Judith L. Bronstein 